\title{
A philosophical framework for enhancing the understanding of artefacts in the technology classroom
}

\author{
Willem Rauscher \\ University of Pretoria, South Africa
}

Correspondence: willem.rauscher@up.ac.za

\begin{abstract}
Technology teachers should have a sound understanding and knowledge of artefacts in order to assist learners in the designing, making, and evaluating of artefacts. Unfortunately, technology teachers in South African schools seem to have a poor grasp of the complexity of this important part of knowledge that is specific to technology. As a result, many technology teachers are unable to support learners in designing and making artefacts that are functional, aesthetically pleasing, and have utility value outside the classroom. This deficiency in their knowledge can, among other things, be attributed to the fact that most technology teachers have not received formal training in technology education. Also, the limited research base and the paucity of subject-based philosophical frameworks in technology education, which could inform classroom pedagogy, exacerbate this situation. Therefore, the purpose of this theoretical essay is to draw on, inter alia, literature from the philosophy of technology to provide an overview of the nature of technical artefacts with a view to creating a framework that will help teachers to understand technical artefacts and be able to teach about them effectively. The framework may be a useful tool for teachers to support learners in designing and making technical artefacts that work properly, are fit-for-purpose, and are well finished. The framework, which provides a structure for designing and developing technical artefacts, may also serve as an instrument to help learners in evaluating existing artefacts, which, in turn, may enhance their understanding of the knowledge that is embedded in artefacts.
\end{abstract}

Keywords: Artefacts; dual nature of artefacts; Dooyeweerd's aspects of reality; Mini-PAT; Technical artefacts

\section{Introduction}

Mitcham (1994) identifies technical artefacts as one of the ways in which technology is manifested. De Vries (2005a) points out that although people may not see much of the process behind technology, the outcomes of these processes, namely artefacts, are everywhere: "Technical artefacts are our immediate encounter with technology" (De Vries, 2005a, p. 13). Developing practical solutions (i.e. artefacts) to solve human needs and wants is, in fact, the primary goal of technology (Department of Basic Education, 2011b). Technical artefacts should, therefore, play a significant role in the pedagogy of technology. 
Opportunities to teach and learn about artefacts in South African schools are provided through short Practical Assessment Tasks (Mini-PATs) in the Curriculum and Assessment Policy Statement (CAPS) for Technology (Grades 7-9) (DoBE, 2011a). A Mini-PAT comprises the main formal assessment of a learner's knowledge and skills during each term, and is intended to formalise the practical component, which is contextualised within each of the four content areas (viz. Structures, Mechanical and Electrical Systems and Control, and Processing) of technology (DoBE, 2011a). The Department of Basic Education (2011a) notes that a Mini-PAT may be an assignment that covers some aspects of the design process, or it could be a capability task (Term 3 of each grade) that addresses the full design process, i.e. Investigate, Design, Make, Evaluate, and Communicate (IDMEC). Although the Mini-PATs vary in the extent to which they address the different phases of the design process in each term of each grade, Design and Make are the two phases that are present in all of the Mini-PATs. Therefore, designing and making an artefact should be seen as a requirement in all Mini-PATs. This consistent requirement should prompt teachers to teach about artefacts.

Teachers being able to support their learners in the designing and making of artefacts that are functional, aesthetically pleasing, and which have utility value outside of the classroom requires a sound understanding of artefacts, and in particular, knowledge about artefacts. Such knowledge, another fundamental mode for the manifestation of technology (Mitcham, 1994), plays a vital role in the development of artefacts. Unfortunately, the vast majority of technology teachers in South Africa has not received formal training in teaching technology during their Initial Professional Education of Teachers (IPET) programmes (Potgieter, 2004). Therefore, they do not have the relevant academic background in all of the content areas as required by the curriculum (Potgieter, 2004). Despite efforts by the Department of Basic Education to provide in-service training, teachers report this training to be inadequate and claim that they still lack the necessary content knowledge to teach technology (Makgato, 2012). Engelbrecht, Ankiewicz and De Swardt (2007) affirm that many technology teachers do not have the relevant knowledge and skills to facilitate technology lessons properly. The deficiency in teachers' knowledge is problematic as it means that teachers will not be able to adequately assist learners in the designing and making of artefacts because they lack a thorough understanding of the complexity of the knowledge that is required to design and make these artefacts. Consequently learners miss out on meaningful engagement with the knowledge that is embedded in the artefacts. De Vries (2005a, p. 38) emphasises the importance of a thorough knowledge of technical artefacts by noting that:

When designing an artifact the designer uses various types of knowledge. It is thanks to this knowledge that artifacts become what they become. One could almost say that the knowledge has been 'absorbed' by the artefact [...] but for someone not having the expertise to recognize what knowledge is in the artifact, the knowledge has just 'disappeared'.

To complicate matters further, technology does not have a profound practical research base, fully developed subject-based philosophical framework, or well-established classroom pedagogy that can be used to inform on such problematic issues (Ankiewicz, 2013, 2015). The purpose of this theoretical essay, thus, is to draw on literature from the philosophy, and specifically from the philosophy of technology, to provide an overview of the nature of technical artefacts, which may be useful in the teaching and learning of technology with a view to creating a framework that may assist teachers in their classroom practice. The article attempts to answer the following 
question: In what ways can a framework that is derived mainly from the philosophy of technology enhance the understanding and teaching of artefacts in the technology classroom? The significance of this question lies in the fact that an exhaustive knowledge and understanding of technical artefacts is required to be able to design and make an artefact that is functional, fitfor-purpose, and aesthetically pleasing whilst considering the possible impact on society and the environment.

\section{Literature review}

The dual nature of technical artefacts

Kroes and Meijers (2006), following a major study on the nature of technical artefacts, concluded that technical artefacts are designed physical structures that are intentionally produced to realise certain goals, i.e. they have a purpose or function. Technical artefacts, therefore, have a dual nature: they are physical structures that embody intentional functions (Kroes, 1998; Kroes \& Meijers, 2006).

The physical nature can be described in terms of the artefact's physical or structural properties (Kroes, 1998). These properties include the size, shape, colour or combination of colours, weight, smell, and the materials that have certain chemical, optical, thermal, electrical, mechanical and magnetic properties (De Vries, 2005b; Frederik, Sonneveld, \& De Vries, 2011). The physical structure thus describes things as they are - these physical descriptions are nonnormative (Frederik et al., 2011).

The functional nature refers to what the artefact ought to do (Frederik et al., 2011). The term "function", in this context, is closely related to human intentionality as technical artefacts are intentionally designed, made and used by people. It is only due "to human intentionality that physical objects become technical artefacts" (Kroes \& Meijers, 2006, p. 1). The function of a technical artefact can therefore not be separated from the context of the intentional use (Kroes, 2001).

Vermaas and Houkes (2006) point out that structural and intentional natures should not be regarded as adversaries, but that the physical structure of an artefact is supplementary to the intention of the designed artefact, and vice versa. Vermaas and Houkes (2006) argue that not only do technical functions connect the physical structures and intentions of technical artefacts, it also allows for these to be separated. Technical functions can be regarded as a "conceptual drawbridge" that relates the physical and intentional natures (Vermaas \& Houkes, 2006, p. 6). Hansson (2006), however, notes that the notion of technical function is multifaceted, and asserts that there are other ways to explicate it than merely to view technical functions as a "conceptual drawbridge". Two types of function ascriptions are highlighted: descriptive function ascriptions and performance function ascriptions (Hansson, 2006). It seems that Vermaas and Houkes (2006) only employed the descriptive notion of function, while the performance notion is also worth considering - especially in relation to the design process. A performance function ascription is successful only to the extent that it gives rise to socially recognised function (Hansson, 2006).

Mitcham (2002) makes two points while commenting on the dual nature of artefacts: one that is historico-philosophical, and the other conceptual. Firstly, a historico-philosophical comparison 
suggests that there is a need to make some conceptual distinctions among the various kinds of artefacts: it could be questioned whether the dual nature of artefacts is the same in each case (Mitcham, 2002). Mitcham (2002), for example, points out that the physical nature (physical or structural properties) and the function of a tool (e.g. a hammer) would not be the same as the physical nature and the function of a computer. He suggests that it would be useful to distinguish the different types of material objects and also to consider how they are designed and used in completely different ways. Mitcham's (2002) second concern, the conceptual issue, arises from the key terms used in the formulation of "dual nature of technical artefacts", for example, the terms "technical artefacts" seem like a pleonasm since all artefacts are the product of some kind of technique. Mitcham (2002) also questions the term "dual nature" and asks why there are only two (i.e. physical nature and functional nature) and not more. Dual (two) may exclude the multitude that may in reality be manifest in this possibility space (Mitcham, 1994).

De Vries (2005a) believes that designing an artefact may require more knowledge than the dual nature that technical artefacts can yield. He suggests that the dual nature of technical artefacts be extended by adding Dooyeweerd's (1969) aspects of reality. Table 1 shows how De Vries (2005a) grouped Dooyeweerd's aspects of reality according to the dual nature of artefacts.

Table 1: Dooyeweerd's aspects of reality grouped according to the dual nature of artefacts

\begin{tabular}{ll}
\hline Dual nature of artefacts & Aspect of reality \\
\hline $\begin{array}{l}\text { Knowledge of the physical nature } \\
\text { of technical artefacts }\end{array}$ & Quantitative \\
(non-intentional aspects) & Spatial \\
& Kinematic \\
& Physical \\
& Biotic/organic \\
& Sensitive/psychic \\
Knowledge of the functional & Analytical \\
nature of technical artefacts & Formative \\
(intentional aspects) & Lingual \\
& Social \\
& Economic \\
& Aesthetic \\
& Juridical \\
& Ethical \\
& Faith \\
\hline
\end{tabular}

This grouping is adapted from De Vries (2005a, p. 37)

The grouping of Dooyeweerd's aspects of reality in Table 1 was done by dividing the nonintentional aspects (in which the artefact can serve as a subject) into the physical nature and the intentional aspects (in which the artefact can only serve as an object to which a subject ascribes a function) into the functional nature of artefacts. De Vries (2005a) asserts that the addition of Dooyeweerd's aspects of reality to the dual nature of artefacts presents a more complete idea of the range and complexity of the knowledge that is required to design an artefact. He also points 
out that a designer should, ideally, consider all these aspects, but acknowledges that there are cases in which only some aspects are of importance, and that in these cases, the other aspects have less of an influence (De Vries, 2005a).

The next section provides an overview of Dooyeweerd's (1969) aspects of reality, as interpreted by Basden (2011), which is listed in Table 1.

\section{Dooyeweerd's suite of aspects}

Dooyeweerd's own discussion of the aspects of reality is lengthy and detailed, but does not provide a practical, orderly discussion of the aspects that may fulfil the needs of multi-aspectual practice (Basden, 2011). According to Basden (2011), this is partly because Dooyeweerd's discussion is often interrupted by deliberations on other interpretations, and partly because it was written to discuss the process of identifying the aspects and not for the purpose of explaining them. While individual aspects have been discussed, there seems to be very little discussion on the kernel meanings of the aspects all together (Basden, 2011). Consequently, Basden (2011) endeavours to provide a practical and organised discussion of Dooyeweerd's suite of aspects as the kernel meanings of these aspects can only be properly understood in relation to each other. For this reason, and since his organised discussion closely resembles De Vries's (2005a) ordering of the aspects (Table 1), this section will be based on Basden's (2011) substantive and methodical analysis and explanation of Dooyeweerd's suite of aspects.

Basden (2011) highlights that Dooyeweerd's aspects are not merely categories or just types of systems or action, but something deeper: they are tightly linked to the actual structure of temporal reality as spheres of meaning, which makes 'being' possible. He notes that 'it is aspectual meaning that makes being of things possible [...] for example, a poem is a poem, qua poem, by virtue of the aesthetic aspect, and at the same time is a piece of writing by virtue of the lingual aspect" (Basden, 2011, p. 4). Also, aspectual meaning cannot be understood by theoretical thought, but only by intuition, and it is therefore impossible to define such meaning precisely (Basden, 2011).

Table 2 provides a summary of Dooyeweerd's fifteen aspects of temporal reality, as adapted from Basden (2011). It shows the aspects grouped into five groups, each consisting of three aspects. All the aspects are of equal importance and are merely ordered into groups according to their kind of functioning: for example, the aspects of human cognition - analytical, formative and lingual - relate to human thought and reasoning, while the social aspects - social, economic and aesthetic - are associated with our living together (Basden, 2011). 
Table 2: Summary of aspects

\begin{tabular}{|c|c|c|c|c|}
\hline $\begin{array}{l}\text { Aspects grouping } \\
\text { (according to the } \\
\text { kind of functioning) }\end{array}$ & Aspect & $\begin{array}{l}\text { Intuitive expression of kernel } \\
\text { meaning } \\
\text { [Good it brings] }\end{array}$ & $\begin{array}{l}\text { Dooyeweerd's rendering of } \\
\text { the kernel meaning }\end{array}$ & Examples of associated concepts \\
\hline \multirow{4}{*}{ Mathematical aspects } & Quantitative & $\begin{array}{l}\text { One, many and several; less and more } \\
\text { [Reliable amount]. }\end{array}$ & $\begin{array}{l}\text { Discrete quantity } \\
\text { (Dooyeweerd, 1969:81). }\end{array}$ & $\begin{array}{l}\text { Amount, quantity, number, average, } \\
\text { minimum, maximum, approximate, fraction, } \\
\text { ratio, addition, division. }\end{array}$ \\
\hline & Spatial & $\begin{array}{l}\text { Here, there, between, inside, around } \\
\text { and outside } \\
\text { [Simultaneity, continuity]. }\end{array}$ & $\begin{array}{l}\text { Continuous extension } \\
\text { (Dooyeweerd, 1969:85). }\end{array}$ & $\begin{array}{l}\text { Shape, size, space, angle, position, area, } \\
\text { distances, orientation, surrounding, holes, } \\
\text { dimension. }\end{array}$ \\
\hline & Kinematic & $\begin{array}{l}\text { Going and continuous flowing } \\
\text { [Change]. }\end{array}$ & $\begin{array}{l}\text { Continuous flowing } \\
\text { (Dooyeweerd, 1969:97). }\end{array}$ & $\begin{array}{l}\text { Expanding, morphing, rotation, route, path } \\
\text { and speed and properties like fast, slow, and } \\
\text { dynamic. }\end{array}$ \\
\hline & Physical & $\begin{array}{l}\text { Forces, energy and matter } \\
\text { [Irreversibility, persistence and } \\
\text { causality]. }\end{array}$ & $\begin{array}{l}\text { Energy } \\
\text { (Dooyeweerd, 1969:99). }\end{array}$ & $\begin{array}{l}\text { Gravity, electromagnetic, weak nuclear and } \\
\text { strong nuclear forces; electricity, friction, } \\
\text { pressure, heat, current, material. }\end{array}$ \\
\hline \multirow[t]{3}{*}{ Pre-human aspects } & Biotic/organic & $\begin{array}{l}\text { Living as organisms in an environment } \\
\text { [Distinct entities that sustain } \\
\text { themselves; reproduce]. }\end{array}$ & $\begin{array}{l}\text { Unity and } \\
\text { multiplicity of life functions } \\
\text { (Dooyeweerd, 1969:109). }\end{array}$ & $\begin{array}{l}\text { Organism, cell, tissue, organ, nutrients, } \\
\text { digestion, respiration, excretion, } \\
\text { reproduction, growth, maturity, death. }\end{array}$ \\
\hline & Sensitive/psychic & $\begin{array}{l}\text { Feeling, sensing and responding } \\
\text { [Interactive engagement with the } \\
\text { world]. }\end{array}$ & $\begin{array}{l}\text { Feeling } \\
\text { (Dooyeweerd, 1969:112). }\end{array}$ & $\begin{array}{l}\text { Eyes, sight and seeing, ears, sound and } \\
\text { hearing, nose, aroma and smelling, hunger, } \\
\text { fear, relaxation, memory, perception. }\end{array}$ \\
\hline & Analytical & $\begin{array}{l}\text { Conceptualising, clarifying, } \\
\text { categorising and cogitating } \\
\text { [Independent and theoretical thinking]. }\end{array}$ & $\begin{array}{l}\text { Analytic mode of distinction } \\
\text { (Dooyeweerd, 1969:118). }\end{array}$ & $\begin{array}{l}\text { Logic, classifying, identifying, thinking, } \\
\text { analysing, reasoning, deducing, distinct, } \\
\text { clear, confusing, cognitive, abstract. }\end{array}$ \\
\hline \multirow[t]{2}{*}{$\begin{array}{l}\text { Aspects of human } \\
\text { cognition }\end{array}$} & Formative & $\begin{array}{l}\text { Deliberate creative shaping of things } \\
\text { [Achievement and innovation]. }\end{array}$ & $\begin{array}{l}\text { Historical development } \\
\text { through formative power } \\
\text { (Dooyeweerd, 1969:202). }\end{array}$ & $\begin{array}{l}\text { Forming, designing, constructing, } \\
\text { processing, controlling, craft, techniques, } \\
\text { structures, well-finished, innovative. }\end{array}$ \\
\hline & Lingual & $\begin{array}{l}\text { Expressing, recording and interpreting } \\
\text { [Externalisation of our intended } \\
\text { meaning; web of meaning]. }\end{array}$ & $\begin{array}{l}\text { Symbolic signification } \\
\text { (Dooyeweerd, 1969:222). }\end{array}$ & $\begin{array}{l}\text { Speak, hear, write, read, gesture, edit, } \\
\text { understandable, sign, symbol, word, text, } \\
\text { sentence, paragraph, language and diagram. }\end{array}$ \\
\hline
\end{tabular}


Social

Social aspects

Economic

Aesthetic

Juridical

\begin{tabular}{ll} 
& Juridica \\
\hline Societal aspects & Ethical
\end{tabular}

Faith
We, us and them; associating, agreeing and appointing [company: togetherness, respect and courtesy].

Managing limited resources frugally [Sustainable viability/prosperity].

Harmonising, enjoying, playing,

beautifying

[Delight that does not seem necessary].

Appropriateness and due for all [Responsibility, policy, law and enforcement].

Intercourse (norms of tact, courtesy, good manners, etc.) (Dooyeweerd, 1969:140).

Frugality

(Dooyeweerd, 1969:67,123).

Harmony

(Dooyeweerd, 1969:128,139).

\section{Retribution}

(Dooyeweerd, 1969:129,130).

Attitude: self-giving love, vulnerability and sacrifice

[Extra goodness, generous attitude].

Vision, commitment, certainty and belief [Courage, loyalty, hope and openness to the Divine].

Faith

(Dooyeweerd, 1969:299).
Relationship, friend, enemy, group, team, club, community, network; authority, leader, subordinate, follower, status, hierarchy; tact.

Goods, customers, orders, business, budgets, deadlines, markets, commons, the economy, money, valuable, rare, careful, sparing.

Aesthetic harmony is in the colours, the effect of light, the sounds, the spatial relations of nature, enjoying food, leisure.

Rights, responsibilities, rules, duty,

urisdiction, owing, judging, just, fair, deserving.

Hospitable, really good (person), voluntary; activities like forgiving, sacrificing, renouncing; agape.
Meaningfulness to our lives, morale, and with things of the Ultimate and Absolute, aspiring, trusting, worshipping, praying.

This is a summary of the article by Basden (2011) 
It should be noted that although each aspect in Table 2 is presented separately, they cannot be separated in reality (Basden, 2011). Dooyeweerd (1969, p. 82), for example, points out that while a proposition such as $2+2=4$ is quantitatively true (quantitative aspect), the answer was deduced from analytical thought (analytical aspect). Also, the + sign is a linguistic symbol (lingual aspect) signifying the positive direction of the temporal order in the originally quantitative sense of number.

Basden (2011) notes that the inherent coherence of the aspects may manifest in at least four types of inter-aspect relationships:

- Order - the aspects form an order in two directions: from earlier to later (foundational direction), or from later to earlier (transcendental direction) (Verkerk, Hoogland, Van der Stoep \& De Vries, 2007). For example, kinematic functioning (e.g. rotation or expansion) depends foundationally on the spatial aspect (e.g. area or distance) and anticipates the physical aspect (e.g. force or energy).

- Dependency - this type of relationship is not the same as the aforementioned order relationship where there is a sequence in the foundational and anticipatory direction. Dependency, in this relationship, means that aspects need each other: functioning in one aspect is dependent on good functioning in another aspect. Social functioning (e.g. relationships or networking), for example, depends on good lingual functioning (e.g. being understandable or language). Basden (2011), in fact, notes that social activity cannot happen without the lingual aspect.

- Analogy - in this relationship the meaning of one aspect is echoed in another aspect, for example, biotic aspects (e.g. birth or environment) find analogy in economic aspects (e.g. customers or valuable).

- Reaching out - functioning in one aspect always embroils another aspect as a target or object. We can, for example, have a feeling (psychic aspect) of space (spatial aspect): this entails a psychic reaching out to spatial (Basden, 2011).

\section{Discussion}

Frederik et al. (2011) conducted an empirical study investigating, amongst other things, teachers' understanding of the dual nature of artefacts (without Dooyeweerd's aspects of reality). This study revealed that the sampled teachers did not fully grasp the concepts associated with the dual nature of artefacts. Their findings indicated that the teachers mentioned more physical properties than functions; wrote functions in the properties column (and vice versa); mismatched concepts in the property column with the concepts in the function column; and seldom recognised that a property may fulfil more than one function (Frederik et al., 2011). This is problematic in view of the fact that Frederik et al. (2011:280) claim that "a full account of a technical artefact can only be given by describing both its function and its physical make-up" and that a "good design is one in which an optimal fit exists between the two natures".

De Vries's (2005a) extension of the dual nature of artefacts (Table 1) - to which he added Dooyeweerd's aspects of reality - may help technology teachers (and learners) to understand the respective features of the physical and functional nature of artefacts: Dooyeweerd's aspects of reality can be used as concepts (or criteria) to provide a detailed description of each of the two 
natures. It is, however, suspected by the author of this paper that the classification of the aspects into two distinct groups (Table 1) may limit the fluidity of teachers' and learners' thinking about artefacts, which Dooyeweerd's aspects of reality make possible. Teachers may, for example, instruct learners to merely use Dooyeweerd's aspects to list the features of an artefact or conceptual design under each of the two natures of artefacts without consciously ascribing an intention or function to each of the choices made in terms of the physical or structural properties of the design.

Also, although Dooyeweerd theoretically separated the aspects for discussion purposes, he emphasised that they cannot be separated in temporal reality as they all work together (Basden, 2011). The discussion of the inter-aspect relationships in the previous section emphasised this inherent coherence of the aspects. This paper thus suggests a modification of De Vries's (2005a) extended framework that may be useful in enhancing teachers' understanding of artefacts in technology. Once teachers have a sound understanding of the knowledge embedded in artefacts, they should be able to assist learners in understanding, designing, making and evaluating their artefacts. Figure 1 shows the modified framework.

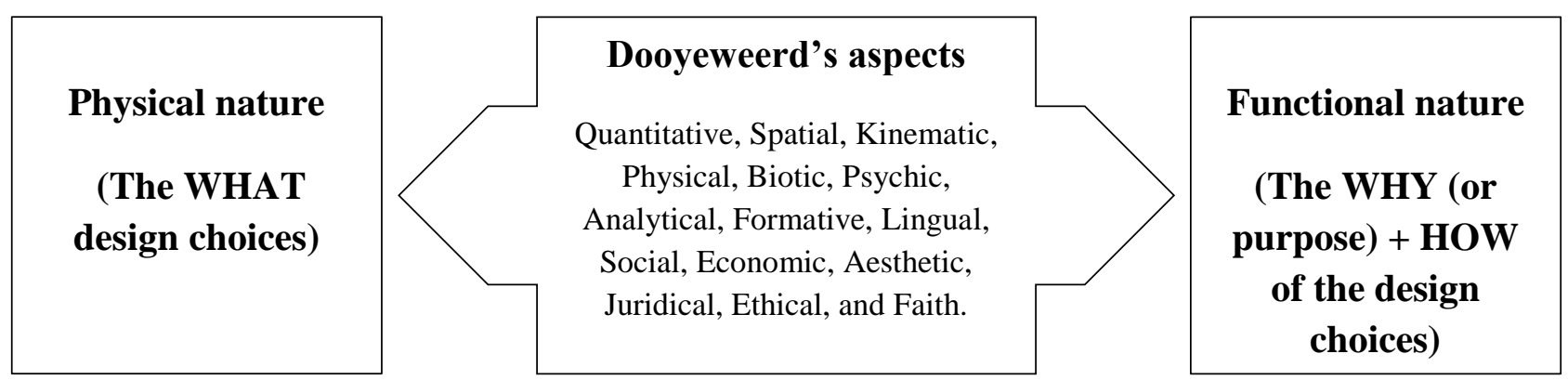

FIGURE 1: Framework for the designing and development of technical artefacts

Instead of separating the aspects into two distinct groups, it is recommended in the modified framework (Figure 1) that Dooyeweerd's aspects of reality be used as a unified group to form a bi-directional link that connects the physical and functional natures of artefacts. Dooyeweerd's aspects of reality can serve as concepts to inform the physical nature, and can then be used to link the physical properties to the functional nature. The bi-directional link in Figure 1 may thus help teachers to assist learners to establish a connection between the WHAT in terms of the physical or structural properties of an artefact; the WHY (intentionality) regarding the physical or structural properties of the artefact; and HOW these physical or structural properties ought to support the function that the artefact should fulfil. The WHAT and WHY questions require learners to consciously consider the physical or structural property choices in terms of the design brief. The HOW question can help learners to think about how these choices could enhance the fitness for purpose of the artefact. Each one of these WHAT, WHY, and HOW questions require a different kind of knowledge that may be better understood when Dooyeweerd's aspects are used as a bi-directional link to connect the physical and functional natures of artefacts. 


\section{Application of the framework in Technology teaching}

The relationship between the framework, which is proposed in Figure 1, and the methodological approach (as required by the CAPS) to teaching technology will now be discussed to indicate how the framework can be used in a technology class to augment the design process.

The design process forms the "backbone" of technology in schools and should be used to structure the teaching of all the content (DoBE, 2011a). The design process thus forms the basis for the teaching methodology of technology. The Department of Basic Education (2011a) expects that at the onset of this process, learners should be exposed to a problem, need or opportunity for which they can develop solutions, solve problems, rectify design issues, and satisfy needs by engaging a systematic process (i.e. design process). The recommended approach is firstly to introduce the relevant content knowledge, followed by practical work (Mini-PAT) in which the knowledge is applied (DoBE, 2011a).

Earlier in this article, it was pointed out that most technology teachers may not have a thorough understanding of the knowledge that is required to design and make artefacts during the MiniPATs. The framework, as proposed in Figure 1, is fully compatible with the design process and can be integrated and used in each phase (IDMEC) of the design process to help teachers to facilitate the Mini-PATs more efficiently. The different aspects of the framework could, for example, provide teachers (and learners) with an array of concepts to think about during each phase of the design process. The rest of this section will explore possible ways in which the framework could help teachers to assist learners during the design process while doing a MiniPAT. The discussion will be limited to the investigating, designing and evaluating phases of the design process since the framework seems to be most useful in these phases.

During the investigating phase of the design process, learners are often required to evaluate existing artefacts (see for example Grade 7, term 2 in the CAPS document). The evaluation of existing artefacts is an effective way to gather ideas that can help learners to generate their own solutions. In addition, and perhaps more significantly, the evaluation of existing artefacts provides teachers the opportunity to make the content knowledge that was learnt prior to doing the Mini-PAT relevant and meaningful to the learners. By engaging with existing artefacts, learners could, for example, see (and feel) what the different components look like and how these components operate within the lager system of the artefact. While learners evaluate existing artefacts, teachers could instruct them to first identify, using Dooyeweerd's aspects as guiding criteria, the physical or structural properties of the artefact (the WHAT things): e.g. the shape(s) and size(s) (Spatial aspect); number of parts/sub-parts (Quantitative aspect); material(s) (Physical aspect); cost(s) (Economic aspect); colour(s) (Aesthetic aspect); and possible sign(s) or symbol(s) (Lingual aspect). Teachers can then ask learners to explain WHY the designer made those physical or structural property choices and HOW those choices contribute towards the function of the artefact. These kinds of exercises, apart from giving learners ideas for their own solutions, may be useful in providing learners some insight into the knowledge that is embedded in artefacts.

During the design phase of the design process, learners must generate several alternative solutions using sketches with explanatory notes (DoBE, 2011a). From a pedagogical perspective, it makes sense that the explanatory notes/annotations accompanying the sketches be as comprehensive and detailed as possible. It is suggested by the author of this paper that these 
explanatory notes/annotations must, inter alia, indicate the WHAT design choices learners make (i.e. physical or structural properties, aka physical nature) when they generate design ideas. Dooyeweerd's aspects of reality, the kernel meaning of each aspect, and the examples shown in Table 2 can aid teachers during the design phase as it provides useful cues to teach learners the many possible WHAT things they ought to consider when they sketch solutions to the problem/need. While learners deliberate the physical or structural properties of their alternative solutions, teachers should help them to connect the WHAT design choices (physical nature) to the function of the artefact. De Vries (2005a) notes that learners should, for instance, not only learn about the properties of materials, but must also understand what material properties make materials suitable for a specific purpose. Teachers can assist learners to do this by asking WHY and HOW questions, for example, why this specific shape (Spatial aspect) or material (Physical aspect) was selected and how these choices will aid the function of the artefact. Dooyeweerd's aspects of reality (Table 2) can, again, provide teachers with the necessary information to facilitate the WHY question. Both the choice of shape and material can perhaps be motivated in terms of the Aesthetic aspect: the shape may provide visual balance, while the material (e.g. glass) may have a beautiful effect on the light. These choices may also be inspired by the Sensitive/Psychic aspect: the way the artefact feels or is perceived by the user of the artefact. In addition, the choice of material can be explained in terms of money (e.g. it is cheap, thus Economic aspect) or for its specific properties (Physical aspect). The HOW question can be addressed in the same way - the shape or material was, for example, chosen because it will provide a better grip during handling or reduce friction during use (Physical aspect). Asking the WHAT, WHY and HOW questions can help teachers to relate the relevant content knowledge to learners' conceptual designs by prompting learners to continuously think about, for example, operating principles; properties of materials; scientific laws; and rules and conventions.

Due to its significance in the design and development of artefacts, evaluation connects all the phases of the design process. It is thus vital that all of the choices that learners make, in every phase of the design process, be evaluated to establish whether these choices improve the fitness for purpose of the artefact in order to develop the best possible solution to the problem/need. If it is found that the WHAT design choices do not support/enhance the function of the artefact, they should be reconsidered and revised. The WHY and HOW explanations must then be repeated using the concepts in Table 2 as cues to inform design choices.

\section{Conclusion}

Mitcham (1994) states that knowledge is one of the modes through which technology is manifested. Various types of knowledge are required to design and make artefacts, which, according to Mitcham (1994), is another mode of the manifestation of technology. To sufficiently support learners in the making of functional and fit-for-purpose artefacts, teachers must have a sound understanding of the wide spectrum of different types of technological knowledge, including knowledge about artefacts. Unfortunately, technology teachers in South African schools seem to have a poor grasp of the complexity of this important part of knowledge that is specific to technology. It is thus vital that knowledge about artefacts be included as a component in the curricula for technology teacher training at higher education institutes in both Initial Professional Education of Teachers (IPET) programmes, as well as Continuing Professional Teacher Development (CPTD) programmes. 
The bi-directional disposition of the framework (Figure 1) seems to fit particularly well with the iterative nature of the design process and may thus be useful during IPET and CPTD training to enhance technology teachers' understanding of artefacts. This, in turn, may enable teachers to help learners in the Mini-PATs/capability tasks to comprehend the physical nature and functional nature of artefacts, and help them to connect the two natures of artefacts. In addition, the framework (Figure 1) could serve as a tool to help learners to evaluate existing artefacts during the investigating phase of the design process. Using the framework to inform evaluations may provide some insight into the various types of knowledge that the designer considered during the designing of the artefact.

Since the conceptual framework (Figure 1) was derived chiefly from the philosophy of technology, it is recommended that the framework be empirically tested in a classroom context. Further research may inform on the framework's usefulness in schools and higher education institutes, and may reveal deficiencies in the framework that need to be addressed.

\section{References}

Ankiewicz, P. (2013). 'n Teoretiese besinning oor die implikasies van die filosofie van tegnologie vir onderwyseropleiding. Suid-Afrikaanse Tydskrif vir Natuurwetenskap en Tegnologie, 31(1), 9.

Ankiewicz, P. (2015). 'n Teoretiese besinning oor die implikasies van die filosofie van tegnologie vir kriteria vir vakkurrikulumontwikkeling en -evaluering. Suid-Afrikaanse Tydskrif vir Natuurwetenskap en Tegnologie, 34(1), 7.

Basden, A. (2011). A presentation of Herman Dooyeweerd's aspects of temporal reality. International Journal of Multi Aspectual Practice, 1(1), 1-28.

De Vries, M. J. (2005a). Teaching about technology: An introduction to the philosophy of technology for non-philosophers. Dordrecht: Springer.

De Vries, M. J. (2005b). The nature of technological knowledge: Philosophical reflections and educational consequences. International Journal of Technology and Design Education, 15(2), 149-154.

Department of Basic Education. (2011a). Curriculum and Assessment Policy Statement for Technology: Senior Phase - Grades 7-9. Pretoria: Government printers.

Department of Basic Education. (2011b). Curriculum and Assessment Policy Statement: Intermediate Phase - Grades 4-6. Pretoria: Government printers.

Dooyeweerd, H. (1969). A new critique of theoretical thought. Part 2. The general theory of the modal spheres (H. de Jongste \& D. H. Freeman, Trans. Second ed.). Philadelphia: The Presbyterian and Reformed Publishing Company.

Engelbrecht, W., Ankiewicz, P., \& De Swardt, E. (2007). An industry-sponsored, school-focused model for continuing professional development of technology teachers. South African Journal of Education, 27(4), 579-595.

Frederik, I., Sonneveld, W., \& De Vries, M. J. (2011). Teaching and learning the nature of technical artifacts. International Journal of Technology and Design Education, 21(3), 277-290.

Hansson, S. O. (2006). Defining technical function. Studies in History and Philosophy of Science Part A, 37(1), 19-22.

Kroes, P. (1998). Technological explanations: the relation between structure and function of technological objects. Society for Philosophy and Technology, 3(3), 1-8. 
Kroes, P. (2001). Technical functions as dispositions: a Critical assessment. Techné: Journal of the Society for Philosophy and Technology, 5(3), 1-16.

Kroes, P., \& Meijers, A. (2006). The dual nature of technical artefacts. Studies in History and Philosophy of Science Part A, 37(1), 1-4.

Makgato, M. (2012). Identifying constructivist methodologies and pedagogic content knowledge in the teaching and learning of technology. Procedia-Social and Behavioral Sciences, 47, 1398-1402.

Mitcham, C. (1994). Thinking through technology. Chicago: The University of Chicago Press.

Mitcham, C. (2002). Do artifacts have dual natures? Two points of commentary on the Delft Project. Techné: Research in Philosophy and Technology, 6(2).

Potgieter, C. (2004). The impact of the implementation of technology education on in-service teacher education in South Africa (impact of technology education in the RSA). International Journal of Technology and Design Education, 14(3), 205-218.

Verkerk, M. J., Hoogland, J., Van der Stoep, J., \& De Vries, M. J. (2007). Denken, ontwerpen, maken: basisboek techniekfilosofie. Amsterdam: Boom.

Vermaas, P. E., \& Houkes, W. (2006). Technical functions: a drawbridge between the intentional and structural natures of technical artefacts. Studies in History and Philosophy of Science Part A, 37(1), 5-18. 